\title{
The applicability of POSSUM and P-POSSUM scores as predictors of morbidity and mortality in colorectal surgery
}

\section{Aplicação dos escores POSSUM e P-POSSUM como preditores de morbimortalidade em cirurgia colorretal}

Maria Emília Carvalho-e-Carvalho"; Fábio lopes de-Queiroz"; Breno Xaia Martins-da-Costa ${ }^{1}$; Marcelo Giusti Werneck-Côrtes'; VINÍCIUS PIRES-ROdRIGUES ${ }^{1}$.

\section{A B S T R A C T}

\begin{abstract}
Objective: to apply the POSSUM and P-POSSUM scores as a tool to predict morbidity and mortality in colorectal surgery. Methods: we conducted a prospective cohort study of 551 patients submitted to colorectal surgery in a colorectal surgery tertiary referral hospital in Brazil. We grouped patients into pre-established risk categories for comparison between expected and observed morbidity and mortality rates by the POSSUM and P-POSSUM Scores. Results: in the POSSUM morbidity analysis, the overall expected morbidity was significantly higher than that observed (39.2\% vs. 15.6\%). The same occurred with patients grouped in categories II (28.9\% x 10.5) and III (64.6\% $x$ $24.5 \%)$. In category I, the expected and observed morbidities were similar (13.7\% x 9.1\%). Regarding the evaluation of mortality, it was statistically higher than that observed in category III patients and in the total number of patients (11.3\% vs. 5.6\%). In categories I and II, we observed the same pattern of category III, but without statistical significance. When evaluating mortality by the P-POSSUM score, the overall expected and observed mortality was similar (5.8\% x 5.6\%). Of the 31 patients who died, $20.2 \%$ underwent emergency procedures and sepsis was the main cause of death. Conclusion: the P-POSSUM score was an accurate tool to predict mortality and could be safely used in this population profile, unlike the POSSUM score.
\end{abstract}

Keywords: Indicators of Morbidity and Mortality. Colorectal Surgery. Mortality. Morbidity

\section{INTRODUCTION}

Perio eriodic auditing of a surgical service is essential to perform a critical evaluation and to gain quality. For this purpose, scores are used to predict postoperative morbidity and mortality. The result of this audit allows for better individual risk prediction, therapeutic planning and resource allocation, and comparison among populations of different geographic areas, with lower risk of failure ${ }^{1-4}$.

Several predictors of morbidity and mortality are available (ASA, APACHE, SAPS II). However, the POSSUM (Physiologic and Operative Severity Score for the Study of Mortality and Morbidity) has been commonly recommended as appropriate for surgical practice ${ }^{2,4-6}$. The POSSUM model, first described in 1991 by Copeland et al. ${ }^{4}$, originally used 62 variables, 48 physiological and 14 surgical. After multivariate analysis techniques, these numbers were reduced to 12 physiological variables and six surgical. The system seeks to predict morbidity and mortality in the first 30 postoperative days and allows comparing the results within the institution over time or performing a cross-sectional comparative analysis with other institutions ${ }^{2,4}$. In the evaluation of morbidity, predetermined postoperative complications are considered, subdivided into infectious (subcutaneous infection, abdominal abscess, anastomotic fistula, pneumonia and sepsis) and non-infectious (cardiac events and pulmonary thromboembolism) $)^{4}$.

This method of outcome evaluation was applied to a large number of patients, but it was observed that the system overestimated mortality, especially for low risk patients. Therefore, the P-POSSUM score (Portsmouth Physiologic and Operative Severity Score for the Study of Mortality and Morbidity) was developed, which, despite using the same variables, is able to reduce the overestimation calculated by POSSUM ${ }^{3,7}$. The P-POSSUM is calculated by adding a regression equation to the POSSUM calculation.

The Coloproctology Clinic of the Felício Rocho Hospital adopted the POSSUM/P-POSSUM system in 
January 2011. The objective of this study was to evaluate the use of the POSSUM system as a tool to predict morbidity and mortality in colorectal surgery by comparing expected and observed POSSUM and P-POSSUM values.

\section{METHODS}

A prospective study, conducted by the Coloproctology Clinic of the Hospital Felício Rocho-BHMG - Brazil, followed Brazilian governmental standards for human research and was approved by the institution's ethics and research committee (CEP), under number 43647815.1.0000.5125.

There were 551 patients undergoing colorectal surgeries enrolled between January 2011 and June 2014. The medical staff filled the protocols for clinical follow-up, specific for each disease, including data on postoperative morbidity and mortality, and later stored in the database maintained by the Coloproctology Clinic. After the surgical procedure, the patient's POSSUM and P-POSSUM were calculated through a risk calculator using the mathematical equation of the POSSUM system, created in Microsoft Excel format. In the service database, we entered the demographic data, the data referring to the surgical procedure and the respective POSSUM and P-POSSUM values.

For analysis of morbidity, we divided the 551 patients into three morbidity categories estimated by POSSUM, validated in previous studies ${ }^{8}$. For the analysis of mortality by POSSUM and P-POSSUM, we grouped the patients into three and four categories of estimated mortality, respectively (Table 1).

Table 1. Categories of morbidity and mortality.

\begin{tabular}{lcccc}
\hline & I & II & III & IV \\
\hline Morbidity & $<20 \%$ & $20-40 \%$ & $>40 \%$ & - \\
POSSUM Mortality & $<5 \%$ & $5-10 \%$ & $>10 \%$ & - \\
P-POSSUM Mortality & $<5 \%$ & $5-10 \%$ & $10-50 \%$ & $>50 \%$ \\
\hline
\end{tabular}

For statistical analysis, we calculated the mean and standard deviation (SD) of the expected morbidity and mortality. We also computed the confidence interval $(95 \% \mathrm{Cl})$ of each category for analysis of morbidity and mortality, allowing comparison between the observed and expected findings. We considered a p-value $<0.05$ as statistically significant. We performed statistical analysis using the SPSS Statistics for Windows, version 19.0 (IBM Corp.).

\section{RESULTS}

With respect to procedures' modality, 83\% (457) of the patients were submitted to elective procedures and $17 \%$ to emergency ones. Two hundred and fifty-seven (46.6\%) patients underwent laparoscopic procedures, with a conversion rate of $6.6 \%$ (Table 2 ).
Table 2 . Surgical procedure.

\begin{tabular}{lc}
\hline \multicolumn{1}{c}{ Patients (n) } & 551 \\
\hline Gender & $314(57 \%)$ \\
Female (\%) & $237(43 \%)$ \\
Male (\%) & \\
Surgical Approach & $257(46.6 \%)$ \\
Laparoscopic (\%) & $294(53.4 \%)$ \\
Open (\%) & $17(6.6 \%)$ \\
Conversion (\%) & \\
Surgical mode & $94(17.1 \%)$ \\
Urgency (\%) & $457(82.9 \%)$ \\
Elective (\%) & $31(5.6 \%)$ \\
Deaths (n) & $19(20.2 \%)$ \\
Urgency (\%) & $12(2.62 \%)$ \\
Elective (\%) &
\end{tabular}


In the POSSUM morbidity analysis, the total expected morbidity was $39.2 \%, 13.7 \%$ being in category I, $28.9 \%$ in category II and $64.6 \%$ in category III. Table 3 shows that the observed morbidity was lower than the predicted one when evaluating general morbidity and in categories II and III $(p<0.05)$. The morbidity of category I patients was lower than the expected, but not statistically significant $(p>0.05)$.

Table 3 . POSSUM morbidity.

\begin{tabular}{lccccccc}
\hline Morbidity & $\mathrm{N}$ & Expected & $95 \% \mathrm{Cl}$ & $\mathrm{N}$ & Observed & $95 \% \mathrm{Cl}$ & $\mathrm{p}$-Value \\
\hline $\mathrm{I}$ & 165 & $13.7 \%$ & $13-14.4$ & 15 & $9.1 \%$ & $1.3-16.9$ & $>0.05$ \\
II & 170 & $28.9 \%$ & $28-29.7$ & 18 & $10.5 \%$ & $2.9-18.2$ & $<0.05$ \\
III & 216 & $64.6 \%$ & $64.6-69$ & 53 & $24.5 \%$ & $17.7-31.3$ & $<0.05$ \\
General & 551 & $39.2 \%$ & $37.1-41.3$ & 86 & $15.6 \%$ & $11.4-19.9$ & $<0.05$ \\
\hline
\end{tabular}

In the evaluation of mortality by the POSSUM score, as shown in table 4, the observed general mortality rate $(5.6 \%)$ and that of category III patients (15\%) was significantly lower than the expected by the POSSSUM system ( $p<0.05)$. In the analysis of categories I and II, we observed a lower than expected mortality, but without statistical significance (I: $0.8 \%$ vs. $3 \% ;$ ill: $1.6 \%$ vs. $6.9 \%$, $p>0.05)$.

Table 4. POSSUM mortality.

\begin{tabular}{lccccccc}
\hline Morbidity & $\mathrm{N}$ & Expected & $95 \% \mathrm{Cl}$ & $\mathrm{N}$ & Observed & $95 \% \mathrm{Cl}$ & $\mathrm{p}$-value \\
\hline $\mathrm{I}$ & 245 & $3 \%$ & $2.9-3.1$ & 2 & $0.8 \%$ & $0-7.2$ & $>0.05$ \\
$\mathrm{II}$ & 126 & $6.9 \%$ & $6.6-7.1$ & 2 & $1.6 \%$ & $0-10.5$ & $>0.05$ \\
III & 180 & $25.8 \%$ & $22.9-28.7$ & 27 & $15 \%$ & $7.5-22.5$ & $<0.05$ \\
General & 551 & $11.3 \%$ & $10-12.6$ & 31 & $5.6 \%$ & $1.4-9.9$ & $<0.05$ \\
\hline
\end{tabular}

When evaluating mortality by the P-POSSUM, the expected general mortality was not different from the observed one ( $5.8 \%$ vs $5.6 \%, p>0.05)$. Table 5 shows that in the separate analysis of each of the four separately, there was no difference between the expected and the observed mortality.

Table 5. P-POSSUM mortality.

\begin{tabular}{lccccccc}
\hline Morbidity & $\mathrm{N}$ & Expected & $95 \% \mathrm{Cl}$ & $\mathrm{N}$ & Observed & $95 \% \mathrm{Cl}$ & $\mathrm{p}$-Value \\
\hline $\mathrm{I}$ & 445 & $1.5 \%$ & $1.4-1.7$ & 8 & $1.8 \%$ & $0-6.5$ & \\
II & 52 & $6.8 \%$ & $6.4-7.2$ & 3 & $5.8 \%$ & $0-19.6$ & \\
III & 37 & $19.7 \%$ & $16.9-22.6$ & 7 & $18.9 \%$ & $2.5-35.4$ & $>0.05$ \\
IV & 17 & $85.2 \%$ & $64.6-100$ & 13 & $76.5 \%$ & $34.6-83.1$ & \\
General & 551 & $5.8 \%$ & $4.5-7.2$ & 31 & $5.6 \%$ & $0.8-9.3$ & \\
\hline
\end{tabular}

The overall mortality rate was $5.62 \%$. Of the patients who died, 19 did after emergency surgery, and 12 , after elective procedures, a mortality rate of $20.2 \%$ and $2.62 \%$, respectively. Sepsis was the main cause of death in $67.7 \%$ of the patients. 


\section{DISCUSSION}

Postoperative morbidity and mortality rates are objective measures of outcomes that can be used to modify behavior and assess the quality of care. Previous studies have evidenced the important role of the POSSUM system as a predictor of postoperative morbidity and mortality5,9,10. A systematic review of the literature that evaluated POSSUM and its variants in patients undergoing surgery for colorectal cancer showed that the POSSUM score was able to predict morbidity in a reliable way and the P-POSSUM was the most accurate predictor of mortality, even when compared with CR-POSSUM ${ }^{1}$. In their prospective study, Chatterjee et al. ${ }^{10}$ evaluated 50 patients with perforating peritonitis. The POSSUM score was a good indicator of postoperative outcome, but the limitations of the study were the sample size and the reliability evaluation of the use of the score in highrisk patients and emergency procedures, preventing its extrapolation to the low-risk population. Oomen et al. ${ }^{11}$ compared the different POSSUM scores in 241 patients submitted to resections for sigmoid tumor or diverticular disease, and did not observe any difference in mortality, showing no mortality predictors specific to each disease.

In the present study, the POSSUM score was able to predict morbidity and mortality with accuracy only in patients with low risk of complications and mortality. In patients with a high risk of morbidity and mortality, there was an overestimation, making the tool flawed and inadequate to evaluate this population profile. On the other hand, P-POSSUM was able to predict morbidity and mortality in a reliable manner when performed by category or general mortality, showing to be a safe and accurate index. With regard to deaths, the rates observed are in line with the data in the literature. Of the thirtyone deaths, the majority were secondary to emergency procedures and in patients who had high morbidity. The implementation of a results evaluation system to analyze the mortality rate as the P-POSSUM in our service was of great value, as it allowed risk stratification. Thus, it was possible to evaluate the results in a timely manner, clearly identifying the situations in need of resources to improve quality. In addition, it allowed the implementation of corrective measures in specific groups aimed at improving results, with targeted interventions.
The POSSUM and P-POSSUM scores were developed based on several surgical procedures. Although studies have shown the value of the POSSUM score in colorectal cancer surgery ${ }^{1,12}$, Tekkis et al..$^{13}$ developed the CR-POSSUM (Colorectal Possum) variation, which uses fewer parameters, facilitating calculation and decreasing variations. The CR-POSSUM evaluates the physiological variables age, cardiovascular system, systolic pressure, pulse rate, hemoglobin and urea, and the surgical variables peritoneal contamination, malignancy status and surgery size. A study comparing POSSUM and CRPOSSUM as predictors of mortality in 120 patients who underwent surgical resection for colorectal cancer showed that P-POSSUM, despite a non-significant overestimation of mortality in $25 \%$, may be used to predict mortality. However, when compared to CR-POSSUM, this variant was more accurate ${ }^{14}$. Two other prospective studies evaluated the use of the POSSUM score to predict morbidity and mortality in colorectal surgeries in 304 and 899 patients ${ }^{15,16}$. In both studies, only CR-POSSUM was accurate in predicting mortality, while POSSUM overestimated morbidity and mortality. P-POSSUM overestimated mortality in the first study and underestimated the risk of dying after surgery in the other ${ }^{16}$. Corroborating with these findings, Constantinides et al. ${ }^{17}$, when evaluating the POSSUM score in 324 patients with complicated diverticulitis, found that CR-POSSUM was able to predict the results more reliable than P-POSSUM.

Our study has as limitations the selected sample. Since it is a high complexity reference hospital, it deals with patients with more complex clinical conditions and, consequently, they are expected to have a greater potential for complications and associated deaths. P-POSSUM proved to be an accurate tool for this high-risk population and it is not possible to safely extrapolate its use to low-risk patients. Data collection by more than one service surgeon was another limiting factor in the study, as it allows subjective data used in the calculation of the score, such as estimated blood loss, to be interpreted differently, leading to variations in the final score result.

The analysis of the population in a stratified manner, by age and by disease, although previously described without a statistical difference in diseasespecific morbidity and mortality ${ }^{12}$, could allow a thorough evaluation, especially with regard to morbidity, enabling 
the implementation of targeted interventions.

The evaluation of the P-POSSUM in a population of low risk is necessary to validate it as suitable for use in a generalized way in the patients submitted to colorectal surgeries in the institution. Regarding morbidity, further studies are needed to validate a score that accurately predicts morbidity in both low and high-risk patients. As seen previously seen ${ }^{14-16}$, the use of CR-POSSUM may be more adequate to the profile of the population studied, but other studies are necessary to validate its adoption.

The data presented show that the P-POSSUM score was able to accurately predict mortality, but the population evaluated was composed of high-risk patients. This score can be safely used in this specific population, allowing for improvements in the postoperative routines and in performing internal audit with regard to mortality.

\title{
RE S U M O
}

\begin{abstract}
Objetivo: aplicar os escores POSSUM e P-POSSUM como ferramenta para predizer morbimortalidade em cirurgia colorretal. Métodos: estudo de coorte prospectivo de 551 pacientes submetidos à cirurgia colorretal em um hospital terciário de referência em cirurgia colorretal no Brasil. Os pacientes foram agrupados em categorias de risco pré-estabelecidas para comparação entre as taxas de morbimortalidade esperada e observada pelo POSSUM e P-POSSUM. Resultados: na análise de morbidade pelo POSSUM, a morbidade geral esperada foi significativamente maior que a observada $(39,2 \% \times 15,6 \%)$. O mesmo ocorreu com os pacientes agrupados na categoria II $(28,9 \%$ x 10,5) e na categoria III $(64,6 \%$ × 24,5\%). Na categoria I, a morbidade esperada e observada foi semelhante (13,7\% x 9,1\%). Com relação à avaliação da mortalidade, esta foi estatisticamente maior do que a observada, nos pacientes da categoria III, e no total dos pacientes $(11,3 \% \times 5,6 \%)$. Nas categorias I e II observou-se o mesmo padrão da categoria III, porém sem significância estatística. Ao avaliar a mortalidade pelo escore P-POSSUM, a mortalidade geral esperada e observada foi semelhante $(5,8 \% \times 5,6 \%)$. Dos 31 pacientes que morreram, 20,2\% foram submetidos a procedimentos de urgência e a sepse foi a principal causa. Conclusão: 0 escore P-POSSUM foi uma ferramenta acurada para predizer mortalidade podendo ser utilizado com segurança neste perfil populacional, ao contrário do escore POSSUM.
\end{abstract}

Descritores: Indicadores de Morbimortalidade. Cirurgia Colorretal. Mortalidade. Morbidade.

\section{REFERENCES}

1. Richards $\mathrm{CH}$, Leitch FE, Horgan PG, McMillan DC. A systematic review of POSSUM and its related models as predictors of post-operative mortality and morbidity in patients undergoing surgery for colorectal cancer. J Gastrointest Surg. 2010;14(10):1511-20.

2. Copeland GP. The POSSUM system of surgical audit. Arch Surg. 2002;137(11):15-9.

3. Prytherch DR, Whiteley MS, Higgins B, Weaver PC, Prout WG, Powell SJ. POSSUM and Portsmouth POSSUM for predicting mortality. Physiological and Operative Severity Score for the enUmeration of Mortality and morbidity. Br J Surg. 1998;85(9):1217-20.

4. Copeland GP, Jones D, Walters M. POSSUM: a scoring system for surgical audit. Br J Surg. 1991;78(3):355-60.

5. Hong $S$, Wang $S, X u G$, Liu J. Evaluation of the POSSUM, p-POSSUM, o-POSSUM, and APACHE ॥ scoring systems in predicting postoperative mortality and morbidity in gastric cancer patients. Asian J Surg. 2017;40(2):89-94. Epub 2015 Sep 26.

6. Tekkis PP, Kocher HM, Bentley AJ, Cullen PT, South
LM, Trotter GA, et al. Operative mortality rates among surgeons: comparison of POSSUM and p-POSSUM scoring systems in gastrointestinal surgery. Dis Colon Rectum. 2000;43(11):1528-32.

7. Whiteley MS, Prytherch DR, Higgins B, Weaver PC, Prout WG. An evaluation of the POSSUM surgical scoring system. Br J Surg. 1996;83(6):812-5.

8. Ren L, Upadhyay AM, Wang L, Li L, Lu J, Fu W. Mortality rate prediction by Physiological and Operative Severity Score for the Enumeration of Mortality and Morbidity (POSSUM), Portsmouth POSSUM and Colorectal POSSUM and the development of new scoring systems in Chinese colorectal cancer patients. Am J Surg. 2009;198(1):31-8.

9. Wang $H$, Wang $H$, Chen $T$, Liang $X$, Song $Y$, Wang J. Evaluation of the POSSUM, P-POSSUM and E-PASS scores in the surgical treatment of hilar cholangiocarcinoma. World J Surg Oncol. 2014;12:191.

10. Chatterjee AS, Renganathan DN. POSSUM: a scoring system for perforative peritonitis. J Clin Diagn Res. 2015;9(4):PC05-9. 
11. Oomen JL, Cuesta MA, Engel AF. Comparison of outcome of POSSUM, p-POSSUM, and cr-POSSUM scoring after elective resection of the sigmoid colon for carcinoma or complicated diverticular disease. Scand J Gastroenterol. 2007;42(7):841-7.

12. Cheung H, Poon JT, Law WL. The impact of POSSUM score on the long-term outcome of patients with rectal cancer. Colorectal Dis. 2013;15(9):1171-6.

13. Tekkis PP, Prytherch DR, Kocher HM, Senapati A, Poloniecki JD, Stamatakis JD, et al. Development of a dedicated risk-adjustment scoring system for colorectal surgery (colorectal POSSUM). Br J Surg. 2004;91(9):1174-82.

14. Horzic M, Kopljar M, Cupurdija K, Bielen DV, Vergles D, Lackovic Z. Comparison of P-POSSUM and CrPOSSUM scores in patients undergoing colorectal cancer resection. Arch Surg. 2007;142(11):1043-8.

15. Bromage SJ, Cunliffe WJ. Validation of the CRPOSSUM risk-adjusted scoring system for major colorectal cancer surgery in a single center. Dis Colon Rectum. 2007;50(2):192-6.

16. Leung E, Ferjani AM, Stellard N, Wong LS. Predicting post-operative mortality in patients undergoing colorectal surgery using P-POSSUM and CR-POSSUM scores: a prospective study. Int J Colorectal Dis. 2009;24(12):1459-64.

17. Constantinides VA, Tekkis PP, Senapati A; Association of Coloproctology of Great Britain and Ireland. Comparison of POSSUM scoring systems and the surgical risk scale in patients undergoing surgery for complicated diverticular disease. Dis Colon Rectum. 2006;49(9):1322-31.

Received in: 11/07/2017

Accepted for publication: 21/09/2017

Conflict of interest: none.

Source of funding: none.

\section{Mailing address:}

Maria Emília Carvalho e Carvalho

E-mail: mariaeccarvalho@gmail.com

(cc) BY 